\title{
Erratum to: Impact of the arc length on GNSS analysis results
}

\author{
Simon Lutz ${ }^{1}$ - Michael Meindl ${ }^{2}$ - Peter Steigenberger ${ }^{3}$ - Gerhard Beutler ${ }^{4}$. \\ Krzysztof Sośnica $^{4,5}$ - Stefan Schaer ${ }^{1}$ - Rolf Dach ${ }^{4}$ - Daniel Arnold ${ }^{4}$. \\ Daniela Thaller $^{6}$ • Adrian Jäggi ${ }^{4}$
}

Published online: 31 March 2016

(C) Springer-Verlag Berlin Heidelberg 2016

\section{Erratum to: J Geod (2016) 90:365-378 DOI 10.1007/s00190-015-0878-1}

The paragraph in Sect. 5.3

"Satellite positions can be compared in the inertial or in the Earth-fixed coordinate system. When comparing them in the inertial system, one checks the consistency of the orbit parameters. When comparing the satellite positions in the terrestrial system one checks in addition the consistency of the EOPs on both days. Here, we only consider the misclosures in the inertial system."

should read as

"Orbit misclosures may refer to the inertial or to the Earthfixed system. Assuming the same observation scenario from

The online version of the original article can be found under doi:10.1007/s00190-015-0878-1.

Simon Lutz

simon.lutz@swisstopo.ch

1 Federal Office of Topography (swisstopo), Seftigenstrasse 264, 3084 Wabern, Switzerland

2 Institute of Geodesy and Photogrammetry, ETH Zürich, Robert-Gnehm-Weg 15, 8093 Zurich, Switzerland

3 Deutsches Zentrum für Luft- und Raumfahrt, German Space Operations Center, Münchener Straße 20, 82234 Weßling, Germany

4 Astronomical Institute, University of Bern, Sidlerstrasse 5, 3012 Bern, Switzerland

5 Institute of Geodesy and Geoinformatics, Wrocław University of Environmental and Life Sciences, Grunwaldzka 53, 50-357 Wrocław, Poland

6 Bundesamt für Kartographie und Geodäsie, Richard-Strauss-Allee 11, 60598 Frankfurt am Main, Germany day to day, orbit misclosures in the Earth-fixed system exclusively characterize the difference of the orbits at the day boundaries in one and the same reference frame. In the inertial system the pole misclosures (Eq. 1) affect the orbit misclosures, as well. Subsequently, we uniquely analyze the orbit misclosures in the inertial system."

The above change does not affect the findings and conclusions of the original paper. 